\title{
Exploring the Relationship Between Maternal Circulating Hormones and Gestational Weight Gain in Women Without Obesity: A Cross-Sectional Study
}

This article was published in the following Dove Press journal: International Journal of Women's Health

\author{
Martha Lappas ${ }^{1,2}$ \\ Ratana Lim (D) ${ }^{1,2}$ \\ Sarah Price ${ }^{3,4}$ \\ Luke A Prendergast ${ }^{5}$ \\ Joseph Proietto 3,4 \\ Elif I Ekinci ${ }^{3,4}$ \\ Priya Sumithran ${ }^{3,4}$
}

'University of Melbourne, Department of Obstetrics and Gynaecology, Melbourne, Australia; ${ }^{2}$ Mercy Hospital for Women, Melbourne, Australia; ${ }^{3}$ University of Melbourne, Department of Medicine (Austin), Melbourne, Australia; ${ }^{4}$ Department of Endocrinology, Austin Health, Melbourne, Australia; ${ }^{5} \mathrm{La}$ Trobe University, Department of Mathematics and Statistics, Bundoora, Australia
Correspondence: Priya Sumithran University of Melbourne, Department of Medicine (Austin), Repatriation Hospital, Level I, Centaur Wing, 300 Waterdale Road, Heidelberg VIC, Melbourne 308I Australia

Tel +6I 394962375

Email priyas@unimelb.edu.au
Background: Central homeostatic regulation of fat stores is attenuated during pregnancy, to allow for adequate fat deposition to support fetal development and lactation. What factors particular to pregnancy facilitate fat accumulation, and why gestational weight gain (GWG) is so variable, are not clear. The aim of this cross-sectional study was to examine the associations between GWG and circulating hormones with known effects on appetite and growth.

Methods: Women without obesity (body mass index, BMI $<30 \mathrm{~kg} / \mathrm{m}^{2}$ ), with a healthy singleton pregnancy, were recruited at the time of delivery by elective Caesarean section at a tertiary obstetric hospital. Women with preterm ( $<37$ weeks) delivery and smokers were excluded. Maternal blood was collected at the time of delivery for measurement of fasting oestradiol, progesterone, prolactin, insulin, leptin, insulin-like growth factor 1 and insulinlike growth factor binding protein 3. Comparisons were made between women who gained weight within the range recommended by Institute of Medicine guidelines for normal weight women (11.5-16 kg; $n=34)$ and those who gained excessive weight $(>16 \mathrm{~kg} ; \mathrm{n}=35)$ during pregnancy. Analysis of covariance was carried out using multiple linear regression to test the effect of GWG group on biochemical parameters, accounting for pre-pregnancy BMI.

Results: The 69 participants had a mean age of $34.6 \pm 4.3$ years, and pre-pregnancy BMI of $\left(23.3 \pm 1.8 \mathrm{~kg} / \mathrm{m}^{2}\right)$, with no significant differences between groups in pre-pregnancy weight, BMI, age, birthweight or parity. Mean GWG was $14.0 \pm 1.3 \mathrm{~kg}$ in the "recommended" group and $19.6 \pm 3.2 \mathrm{~kg}$ in the "excessive" group. Leptin was significantly higher (43.4 $\pm 21.6 \mathrm{vs}$ $33.4 \pm 15.0 \mathrm{ng} / \mathrm{mL}, \mathrm{p}=0.03)$ and prolactin tended to be lower $(159.5 \pm 66.1$ vs $194.0 \pm 85.6$ $\mathrm{ng} / \mathrm{mL}, \mathrm{p}=0.07$ ) at delivery in women with excessive (vs recommended) GWG. No other circulating factors were found to differ between groups. The between-group difference in leptin remained after adjustment for pre-pregnancy BMI in multiple linear regression and quantile regression analyses.

Conclusion: In women without obesity, leptin remains a marker of adiposity during pregnancy. GWG was not associated with other circulating hormones with effects on appetite and growth.

Keywords: gestational weight gain, leptin, pregnancy, appetite

\section{Introduction}

Despite day to day variations in food intake and physical activity, most adults hold a fairly steady body weight over time, because a feedback system between the brain and peripheral organs (including adipose tissue, gastrointestinal tract and pancreas) modulates appetite and energy expenditure in order to maintain a stable level of fat stores. $^{1,2}$ 
Substantial weight gain and fat deposition are required during pregnancy to support fetal development and prepare for the metabolic demands of lactation. The Institute of Medicine (IOM) of the US National Academy of Sciences recommends that women of normal weight (body mass index [BMI] 18.5-24.9 kg/m²) gain between 11.5 and $16 \mathrm{~kg}$ during pregnancy. ${ }^{3}$ After accounting for the weight of the fetus, placenta, amniotic fluid, and physiological expansions in blood volume, extravascular water, uterine and breast tissue, ${ }^{4}$ this allows for deposition of approximately 2.5 to $7 \mathrm{~kg}$ of fat mass.

Appetite and food intake tend to increase in the second and third trimesters of pregnancy ${ }^{5}$ despite an increase in body fat and maternal circulating leptin (a key hormone in energy homeostasis), ${ }^{6}$ suggesting that the usual regulation of fat stores must be attenuated or suspended. This concept is supported by the demonstration of central resistance to the appetite-reducing effects of leptin, cholecystokinin and $\alpha$-melanocyte stimulating hormone ( $\alpha$-MSH) during pregnancy. ${ }^{7,8}$ Furthermore, excessive gestational weight gain (GWG) is common, even among women of previously normal weight (BMI 18.5-24.9 $\mathrm{kg} / \mathrm{m}^{2}$ ) - 40\% gain in excess of the IOM recommendation of $16 \mathrm{~kg}$ during gestation, primarily due to increased deposition of fat. ${ }^{3}$

What factors particular to pregnancy facilitate fat accumulation, and why weight gain is so variable, even for women without a previously apparent predisposition to obesity, are not clear. It is plausible that the profound changes which occur during pregnancy in circulating levels of hormones known to stimulate appetite and somatic growth play a role. For example, there are marked increases in maternal circulating levels of progesterone and prolactin, both of which have been shown to stimulate food intake in rats, ${ }^{9,10}$ and the anabolic hormone insulinlike growth factor 1 (IGF-1), which is driven by placental production of growth hormone. ${ }^{11}$ The aim of this study was to examine the associations between GWG and circulating hormones with known effects on appetite and growth. We hypothesized that one or more of these hormones would differ between women who gained $11.5-16 \mathrm{~kg}$ vs more than $16 \mathrm{~kg}$ (within or above IOM recommendations for GWG in normal weight women).

\section{Subjects, Materials and Methods Participants and Setting}

This analysis involved 69 pregnant women without preexisting obesity (pre-pregnancy BMI $<30 \mathrm{~kg} / \mathrm{m}^{2}$ ), aged
20-40 years old, with a healthy singleton pregnancy, who were recruited at Mercy Hospital for Women, a tertiary obstetric hospital in Melbourne, Australia, between 2008 and 2018 for a larger longitudinal study investigating molecular mechanisms controlling pregnancy. The study was approved and by the Mercy Health Human Research Ethics Committee (R04/29), conducted in accordance with the Declaration of Helsinki, and participants provided written informed consent. Women were recruited at the time of admission for term ( $\geq 37$ weeks) delivery by elective Caesarean section. Only women scheduled for elective Caesarean delivery were recruited, to avoid the effects of labour on endpoints. Indications for Caesarean section were breech presentation and/or previous Caesarean delivery. Women who underwent fertility treatment for their current pregnancy, who smoked, took medications with effects on body weight (other than thyroxine), had pre-existing diabetes, asthma, polycystic ovary syndrome, multiple pregnancies, or complications of the current pregnancy (e.g. gestational diabetes, preeclampsia) were excluded. Women were weighed at the time of admission for delivery by clinical staff as part of standard clinical care. Pre-pregnancy weight was reported by participants at the time of delivery. For this analysis, GWG was defined as the difference between measured weight at delivery (week 37-41) and selfreported pre-pregnancy weight.

\section{Sample Collection and Assays}

Maternal blood was collected after a 10-12 hour fast, approximately 30 minutes prior to scheduled Caesarean delivery, into a vacuum EDTA tube, centrifuged at $1000 \mathrm{~g}$ for $5 \mathrm{~min}$, the plasma aliquoted into $1 \mathrm{~mL}$ microfuge tubes, and stored at $-80^{\circ} \mathrm{C}$ until analysis. Oestradiol and progesterone were measured by immunoassay (Roche Cobas e602 analyser). Insulin was measured using a kit from ALPCO (Salem, NH, USA). Leptin measurements were performed using Quantikine ELISA kits (R\&D Systems, Minneapolis, USA). Prolactin, free insulin-like growth factor 1 (IGF-1) and total insulin-like growth factor binding protein 3 (IGFBP-3) levels were analysed using single-plex magnetic bead assays (Millipore, Billerica, MA, USA). All assays were performed according to the manufacturers' instructions and calculated inter-assay and intra-assay coefficients of variation were all less than $10 \%$. The IGF-1 to IGFBP-3 molar ratio was calculated as an indicator of IGF-1 bioavailability, using the formula: (IGF-1 (ng/mL)*0.13/IGFBP-3 (ng/mL)*0.036). ${ }^{12}$ 


\section{Statistical Analyses}

Descriptive characteristics and biochemical variables are given as means \pm standard deviations (SD) or counts (proportions) unless otherwise stated and compared between groups using independent sample t-tests and Fisher's exact tests, respectively. Women were categorized into two groups for analyses, according to whether the amount of weight gained during pregnancy was excessive $(>16 \mathrm{~kg} ; \mathrm{n}=35)$ or recommended (11.5-16 kg; $\mathrm{n}=34)$ for women of normal weight by IOM guidelines. Analysis of covariance (ANCOVA) was carried out using multiple linear regression to test the effect of gestational weight gain group on hormone levels while accounting for pre-pregnancy BMI. Residuals were visualized to ensure that there were no noticeable violations of model assumptions. Due to the presence of some outliers, and to ensure robustness of findings, quantile regression was also used to model the difference in medians between the groups, while adjusting for prepregnancy BMI. There were no missing data. No adjustment for multiple testing was performed; $p<0.05$ was considered indicative of statistical significance. Analyses were conducted using R version 3.4.0 (R Foundation for Statistical Computing, Vienna, Austria).

\section{Results}

Descriptive baseline characteristics of the women included are given in (Table 1). Mean GWG was $14.0 \pm 1.3 \mathrm{~kg}$ (recommended) and 19.6 $\pm 3.2 \mathrm{~kg}$ (excessive). No significant differences were detected between groups in prepregnancy weight, BMI, age, birthweight or parity.

Differences in circulating factors between groups are shown in (Figure 1). Compared to women who gained weight within the recommended range, leptin was significantly higher $(43.4 \pm 21.6$ vs $33.4 \pm 15.0 \mathrm{ng} / \mathrm{mL}, \mathrm{p}=0.03)$ and prolactin tended to be lower $(159.5 \pm 66.1$ vs $194.0 \pm 85.6 \mathrm{ng} / \mathrm{mL}$, $\mathrm{p}=0.07$ ) at delivery in women with excessive GWG. No significant differences were detected between groups in circulating oestradiol, progesterone, insulin, IGF-1 or IGFBP-3 (Figure 1).

The difference in leptin between groups remained statistically significant after adjustment for pre-pregnancy BMI in multiple linear regression and quantile regression analyses (Table 2). Analyses considering GWG as a continuous variable also found a strong relationship between leptin and GWG $(+1.88 \mathrm{ng} / \mathrm{mL}$ per $1 \mathrm{~kg}$ increase in GWG, $\mathrm{p}=0.001)$, and no significant relationships between GWG and the other circulating factors measured (Table 3).
Table I Baseline Characteristics of Participants

\begin{tabular}{|c|c|c|c|}
\hline & $\begin{array}{l}\text { Recommended } \\
(n=34)\end{array}$ & $\begin{array}{l}\text { Excessive } \\
(n=35)\end{array}$ & p-value \\
\hline GWG & $14.0 \pm 1.3$ & $19.6 \pm 3.2$ & $<0.001$ \\
\hline $\begin{array}{l}\text { Pre-pregnancy BMI } \\
\left(\mathrm{kg} / \mathrm{m}^{2}\right)\end{array}$ & $23.2 \pm 1.8$ & $23.4 \pm 1.8$ & 0.79 \\
\hline $\begin{array}{l}\text { Pre-pregnancy weight } \\
\text { (kg) }\end{array}$ & $62.1 \pm 5.7$ & $64.2 \pm 6.0$ & 0.15 \\
\hline Age (years) & $34.3 \pm 4.1$ & $34.9 \pm 4.6$ & 0.54 \\
\hline Ethnicity & & & 0.38 \\
\hline Caucasian & 24 (7।\%) & $30(86 \%)$ & \\
\hline South Asian & $4(12 \%)$ & $3(9 \%)$ & \\
\hline East/Southeast Asian & $5(15 \%)$ & $2(6 \%)$ & \\
\hline Unknown & I (3\%) & 0 & \\
\hline Parity & & & 0.38 \\
\hline 1 & $4(12 \%)$ & $6(17 \%)$ & \\
\hline 2 & 24 (7I\%) & $18(51 \%)$ & \\
\hline 3 & $5(15 \%)$ & $10(29 \%)$ & \\
\hline 4 & I (3\%) & I (3\%) & \\
\hline Length of gestation (d) & $272 \pm 3$ & $273 \pm 5$ & 0.22 \\
\hline Birth weight (g) & $3471 \pm 363$ & $3565 \pm 394$ & 0.31 \\
\hline Fetal length $(\mathrm{cm})$ & $50.7 \pm 2.0$ & $51.5 \pm 2.0$ & 0.10 \\
\hline Placental weight (g) & $687 \pm 128$ & $672 \pm 116$ & 0.64 \\
\hline
\end{tabular}

No significant differences were detected in molar ratio of IGF-1 to IGFBP-3 between women with excessive vs recommended GWG $(0.07 \pm 0.03$ vs $0.06 \pm 0.02 ; p=0.13)$. Analyses conducted after reclassifying 12 women with BMI $25.1-26.9 \mathrm{~kg} / \mathrm{m}^{2}$ according to IOM recommendations for GWG in overweight women (excessive defined as $>11.4 \mathrm{~kg}$ ) did not significantly alter the results (recommended $n=28$ vs excessive $n=41$, leptin $31.9 \pm 14.1$ vs $43.0 \pm 21.0, \mathrm{p}=0.018$; prolactin $204.8 \pm 87.1$ vs $157.2 \pm$ $64.8, \mathrm{p}=0.012$, remainder of circulating factors not significantly different between groups).

\section{Discussion}

Although appetite and energy expenditure are adjusted to maintain relative weight stability during adulthood, control of body weight homeostasis appears to be modified during pregnancy to accommodate the fat deposition required to support fetal development and lactation. Even among women without an apparent predisposition to obesity, excessive weight gain during pregnancy is common, affecting $40 \%$ of normal weight women. ${ }^{3}$ We hypothesized that variability in gestational weight gain in women without obesity would be associated with circulating hormones known to affect appetite and growth, which are altered 


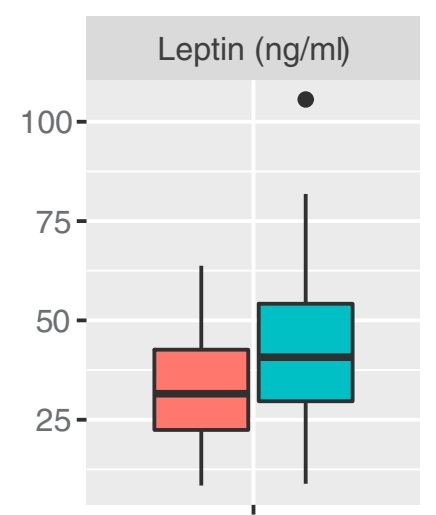

Leptin (ng/ml)

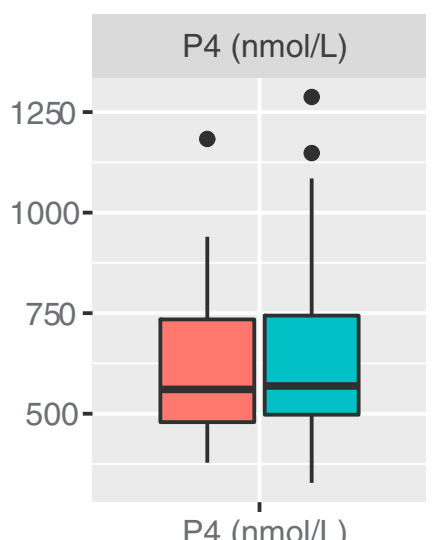

P4 (nmol/L)

IGFBP3 (ng/m)|

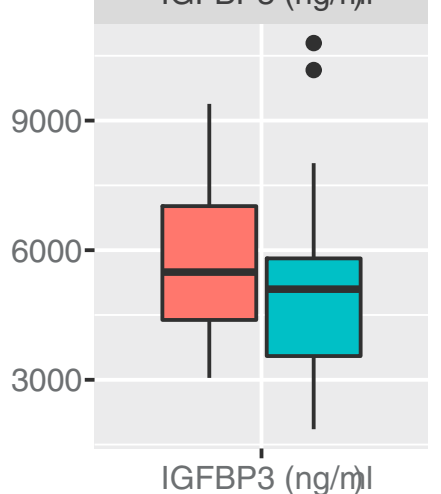

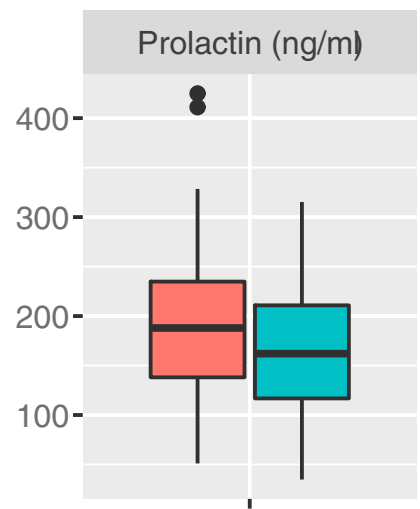

Prolactin (ng/m)

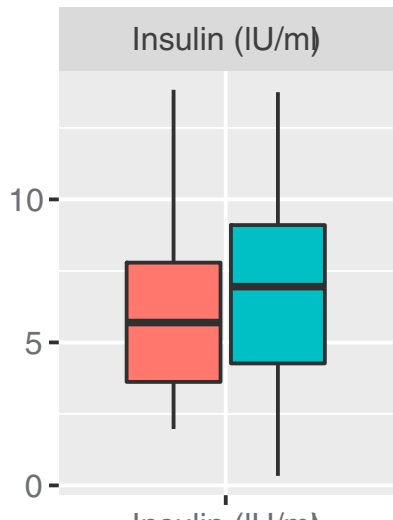

Insulin (IU/m)

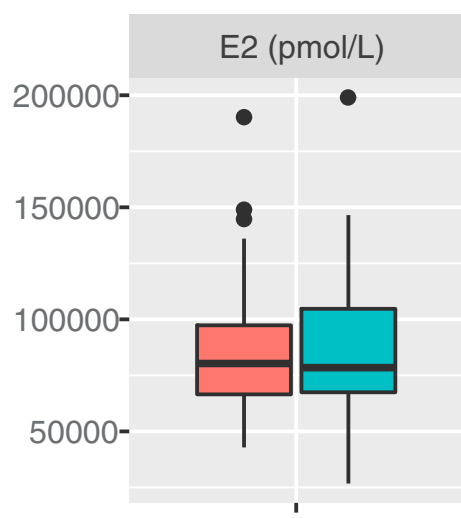

E2 (pmol/L)

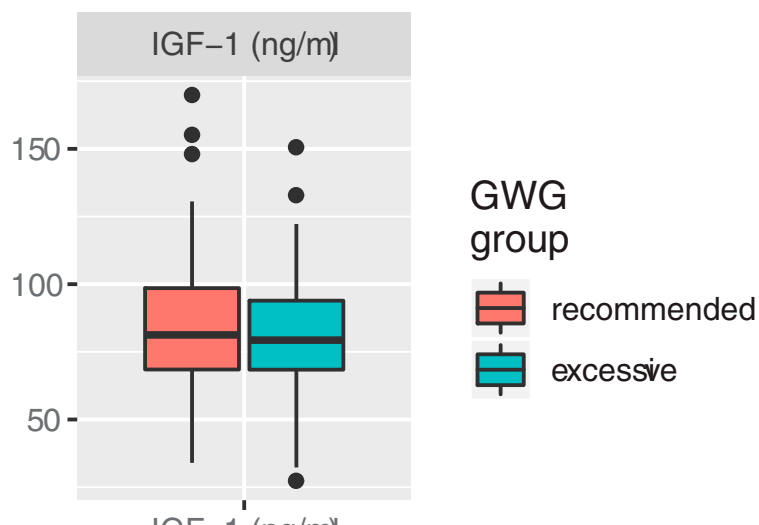

IGF-1 (ng/m)|

Figure I Difference in circulating factors between women with recommended $(n=34)$ vs excessive $(n=35)$ gestational weight gain.

during pregnancy. Our results did not support this, showing only a strong relationship between GWG and circulating leptin at delivery. There was an indication of an inverse relationship between GWG and prolactin which did not reach statistical significance, and no relationship was found between GWG and progesterone, oestradiol, insulin, IGF-1 or IGFBP-3.

Outside of pregnancy, leptin is predominantly produced in white adipose tissue in proportion to fat mass, and transported across the blood-brain barrier, where it inhibits orexigenic agouti-related peptide (AgRP) and neuropeptide Y (NPY) neurones and activates anorexigenic pro-opiomelanocortin (POMC) neurones in the hypothalamus. ${ }^{13}$ Despite the increase in circulating leptin seen in pregnancy, maternal appetite and food intake generally increase, indicating resistance to its effects on appetite. Studies in rats have demonstrated several mechanisms by which central leptin resistance develops in midpregnancy, including reduced transport across the bloodbrain barrier $^{14}$ and impaired hypothalamic signalling. ${ }^{15}$ Human studies indicate similar processes, showing an orexigenic pattern of the neurotransmitters AgRP and 
Table 2 Estimated Mean and Median Differences in Circulating Factors Between Women with Recommended ( $n=34)$ Vs Excessive $(n=35)$ Gestational Weight Gain in Linear (Mean) and Quantile (Median) Regression Analyses Adjusting for Pre-Pregnancy BMI

\begin{tabular}{|l|l|l|l|l|}
\hline & $\begin{array}{l}\text { Estimated Mean } \\
\text { Difference }\end{array}$ & $\begin{array}{l}\mathbf{9 5 \%} \text { Cl for Mean } \\
\text { Difference }\end{array}$ & $\begin{array}{l}\text { Estimated Median } \\
\text { Difference }\end{array}$ & $\begin{array}{l}\mathbf{9 5 \%} \text { Cl for Median } \\
\text { Difference }\end{array}$ \\
\hline Leptin $(\mathrm{ng} / \mathrm{mL})$ & 9.45 & $1.31,17.58$ & 5.59 & $0.68,10.94$ \\
Prolactin $(\mathrm{ng} / \mathrm{mL})$ & -34.3 & $-71.3,2.7$ & -31.2 & $-57.3,15.4$ \\
Oestradiol $(\mathrm{pmol} / \mathrm{L})$ & -658.7 & $-16,349.3,15,031.9$ & -3210.9 & $-11,451.9,11,642.8$ \\
Progesterone $(\mathrm{nmol} / \mathrm{L})$ & 42.4 & $-57.2,141.9$ & 24.8 & $-37.9,123.8$ \\
Insulin $(\mathrm{IU} / \mathrm{mL})$ & 3.43 & $-4.04,10.89$ & 8.43 & $0.02,17.79$ \\
IGF-I $(\mathrm{ng} / \mathrm{mL})$ & -4.43 & $-17.17,8.31$ & -4.27 & $-14.65,4.15$ \\
IGFBP-3 $(\mathrm{ng} / \mathrm{mL})$ & -655.2 & $-1586.2,275.9$ & -430.6 & $-1530.0,564.7$ \\
\hline
\end{tabular}

Table 3 Regression Analyses for Relationship Between Circulating Factors and GWG as a Continuous Variable, Adjusting for PrePregnancy BMI.

\begin{tabular}{|l|l|l|}
\hline & $\begin{array}{l}\text { Estimated Mean } \\
\text { Difference }\end{array}$ & $\begin{array}{l}\text { 95\% Cl for Mean } \\
\text { Difference }\end{array}$ \\
\hline Leptin $(\mathrm{ng} / \mathrm{mL})$ & 1.88 & $0.81,2.95$ \\
Prolactin $(\mathrm{ng} / \mathrm{mL})$ & $-3.1 \mathrm{I}$ & $-8.28,2.07$ \\
Estradiol $(\mathrm{pmol} / \mathrm{L})$ & -983.6 & $-3134.3,1167.0$ \\
Progesterone $(\mathrm{nmol} / \mathrm{L})$ & -0.48 & $-14.29,13.32$ \\
Insulin $(\mathrm{IU} / \mathrm{mL})$ & 0.40 & $-0.63,1.44$ \\
IGF-I $(\mathrm{ng} / \mathrm{mL})$ & 0.02 & $-1.75,1.78$ \\
IGFBP-3 $(\mathrm{ng} / \mathrm{mL})$ & -61.1 & $-190.6,68.3$ \\
\hline
\end{tabular}

Note: Values are expressed as change in circulating factor for I kg increase in GWG

POMC in the cerebrospinal fluid (CSF), and a lower ratio of CSF to plasma leptin in pregnant compared with nonpregnant women. ${ }^{16}$ A recent longitudinal study reported an increase in CSF:peripheral leptin ratio after delivery, and indicated that peripheral AgRP levels in late pregnancy might predict longer-term (5 year) weight changes. ${ }^{17}$

The finding that circulating leptin at delivery was associated with maternal weight and GWG is consistent with other studies which have reported cross-sectional associations between maternal leptin and GWG in different populations or time points, including at 10-20, 30 and 36 weeks, in adults and adolescents, across a range of BMI categories. ${ }^{18-21}$ Some of these studies also reported significant correlations between maternal circulating leptin in late pregnancy and maternal weight or fat mass prior to and in late pregnancy, consistent with our findings. ${ }^{6,19,20}$ Longitudinal studies have reported the associations between circulating leptin and subsequent GWG in normal weight and overweight women, but not in women with obesity. $^{22-24}$ One study in a normal weight population reported that maternal leptin concentration in early pregnancy predicted weight retention at 6 weeks and 6 months postpartum. ${ }^{24}$ Overall, these findings are compatible with maternal circulating leptin being an indicator of adiposity, and of future weight trajectory, in pregnant women without obesity. This is somewhat unexpected, because during pregnancy, fat mass is not the only determinant of maternal leptin - over $90 \%$ of the total increase in circulating leptin which occurs during pregnancy takes place in early gestation, before a significant increase in fat mass, ${ }^{6}$ and levels fall rapidly within $48-72$ hours of delivery. ${ }^{25,26}$ Leptin secretion from adipocytes is stimulated by human chorionic gonadotropin (hCG) and oestradiol, ${ }^{26}$ and the placenta is an additional source of leptin during pregnancy, more than $95 \%$ of which enters the maternal circulation. ${ }^{27,28}$ The purpose of placental leptin production is unclear, but given that increased food intake and fat deposition are desirable, and are facilitated by the development of central resistance to the anorexigenic effects of leptin, it can be inferred that the primary role of placental leptin is unrelated to maternal weight homeostasis. It has been proposed that increased leptin in the maternal circulation may enhance the mobilization of fat stores and support transplacental transfer of lipid substrates. ${ }^{25}$ Leptin receptors are also present within placental tissue, and there is evidence of a local effect of leptin on placental growth, trophoblast invasion and immunomodulation. ${ }^{29-31}$

Increased food intake and weight gain in pregnancy begin prior to the development of leptin resistance. Marked changes in circulating hormones are a likely driver for this, as many reproductive hormones have been shown to influence appetite and body weight. For example, circulating progesterone begins to increase in the first trimester, and peaks at the end of gestation 10-fold above prepregnant levels. ${ }^{32}$ Prolactin levels increase approximately 4-fold during the first trimester, and by a similar magnitude in the second half of pregnancy. ${ }^{32}$ The growth-promoting 
peptide IGF-1 increases progressively in the maternal circulation throughout pregnancy. ${ }^{33}$ Its biological activity is modulated by six binding proteins (IGFBPs), primarily IGFBP-3. ${ }^{34}$ Progesterone and prolactin have been shown to stimulate food intake and weight gain in rats, whereas oestradiol has the opposite effect. ${ }^{9,35,36}$ Prolactin is also likely to play a role in the development of leptinresistance during pregnancy, as intracerebroventricular infusion of prolactin impairs leptin signalling in the ventromedial and paraventricular nuclei. ${ }^{37}$ It is therefore surprising that there was the suggestion of an inverse relationship between GWG and prolactin, although this did not reach statistical significance, and the circulating level is not necessarily an indicator of hypothalamic levels or activity of prolactin. We also found no relationships between GWG and progesterone, oestradiol, insulin, IGF-1 and IGFBP-3. These results are in contrast with a smaller $(n=21)$ crosssectional study, which found increased serum IGFBP-3 expression at the time of delivery in women with excessive compared with recommended GWG. ${ }^{38}$ This difference is likely to be due to variations in methodology used to assess circulating IGFBP-3 between studies, as well as the excess GWG group being considerably heavier prior to pregnancy than the recommended group (BMI $32.7 \mathrm{vs} 24.5 \mathrm{~kg} / \mathrm{m}^{2}$ ) in the earlier study. ${ }^{38}$

How the homeostatic regulation of fat stores is overcome during pregnancy, and what factors underlie the wide inter-individual variability in GWG remain unclear. As is the case for variability in predisposition to weight gain outside the setting of pregnancy, genetic factors appear to contribute. In a twin study, the heritability of GWG in primiparous women was estimated at $43 \%{ }^{39}$ A genomewide association study indicated that around half of this (20\%) may be explained by common maternal genetic variants, with the fetal genome making a much smaller contribution, although no genetic variants were identified which reached genome-wide levels of significance and which replicated. ${ }^{40}$ Sociodemographic and lifestyle factors such as maternal ethnicity, parity, and smoking during pregnancy, have also been associated with a higher risk of excessive gestational weight gain. ${ }^{41}$ It has also been proposed that gut microbes may play a role in weight gain during pregnancy. One study reported that gut microbial profile changed profoundly during pregnancy, and that transfer of third trimester stool microbes from healthy weight pregnant women to germ-free female mice induced greater cecal inflammation, higher circulating glucose at 30 minutes during oral glucose tolerance test, and a tendency towards greater adiposity compared with recipients of first trimester microbes. ${ }^{42}$ Whether differences in gut microbiome contribute to inter-individual variability in GWG is not known.

The major limitations of this study are its observational and cross-sectional nature. This means it cannot provide insight on relationships between GWG and the circulating factors of interest earlier in the course of the pregnancy, which may no longer be detectable at the time of delivery. However, longitudinal studies have not reported consistent associations between circulating markers earlier in pregnancy with subsequent GWG. In a report of 270 Caucasian normal weight women, GWG was found to be unrelated to prolactin at weeks 16 and 27 of gestation, and inversely related to progesterone at week 16 but not week $27,,^{43}$ whereas another study of 226 women found a small association between increases in weight and progesterone levels between gestational weeks 12 and $33 .{ }^{44}$ Furthermore, this type of study can describe the associations between biochemical endpoints and GWG, but provide no indication of causation. Our analyses adjusted for the potential confounding effect on GWG of pre-pregnancy BMI, and excluded women with preterm delivery ( $<37$ week) and smokers to minimise the effects of confounding by age and smoking. While there were no significant differences between groups in birthweight, ethnicity and parity, we cannot exclude residual or unmeasured confounding factors. Other limitations include the unavailability of body composition (in particular, fat mass) and energy intake data, and the reliance on self-reported pre-pregnancy weight, although a systematic review concluded that the magnitude of error in self-reported maternal weight is small. ${ }^{45}$ In order to minimize expected differences in predisposition to excessive weight gain, circulating hormones and recommendations for weight gain, our study included only women without pre-pregnancy obesity, therefore the findings cannot be assumed to be applicable to women with obesity. Finally, central levels and sensitivity to hormone effects cannot be inferred from their circulating concentrations. Although this study included only women scheduled for delivery by elective Caesarean section, participants had no pre-existing obesity and had uncomplicated pregnancies (indications for Caesarean section were breech presentation and/or previous Caesarean delivery), therefore the findings are expected to be generalisable to women with similar characteristics who undergo vaginal deliveries.

In summary, this study of healthy pregnant women without obesity found a strong relationship between 
GWG and circulating leptin at delivery, and no associations between GWG and other circulating hormones associated with appetite and growth. This indicates that leptin remains a marker of adiposity during pregnancy in women without obesity.

\section{Disclosure}

Prof. Dr Joseph Proietto reports personal fees from Novo Nordisk, personal fees from iNova, outside the submitted work. Dr Priya Sumithran reports personal fees from Novo Nordisk, outside the submitted work. Dr Elif I Ekinci reports research funding to EIE's institution from Novo Nordisk, Gilead, Bayer, Sanofi; and grants from NHMRC, grants from Sir Edward Weary Dunlop Foundation, grants from JDRF, outside the submitted work. The authors report no other conflict of interest in relation to this work.

\section{References}

1. Sumithran P, Prendergast LA, Delbridge E, et al. Long-term persistence of hormonal adaptations to weight loss. $N \mathrm{Engl} \mathrm{J} \mathrm{Med}$. 2011;365(17):1597-1604. doi:10.1056/NEJMoa1105816

2. Sumithran P, Proietto J. The defence of body weight: a physiological basis for weight regain after weight loss. Clin Sci. 2013;124 (4):231-241. doi:10.1042/CS20120223

3. IOM (Institute of Medicine) and NRC (National Research Council). Weight Gain During Pregnancy: Reexamining the Guidelines. Washington, DC: The National Academies Press; 2009.

4. Barbour LA. Weight gain in pregnancy: is less truly more for mother and infant? Obstet Med. 2012;5(2):58-64. doi:10.1258/om.2012.120004

5. Wade GN, Schneider JE. Metabolic fuels and reproduction in female mammals. Neurosci Biobehav Rev. 1992;16(2):235-272. doi:10.1016/ S0149-7634(05)80183-6

6. Highman TJ, Friedman JE, Huston LP, et al. Longitudinal changes in maternal serum leptin concentrations, body composition, and resting metabolic rate in pregnancy. Am J Obstet Gynecol. 1998;178 (5):1010-1015. doi:10.1016/S0002-9378(98)70540-X

7. Ladyman SR, Sapsford TJ, Grattan DR. Loss of acute satiety response to cholecystokinin in pregnant rats. $J$ Neuroendocrinol. 2011;23(11):1091-1098. doi:10.1111/j.1365-2826.2011.02191.x

8. Ladyman SR, Augustine RA, Scherf E, et al. Attenuated hypothalamic responses to alpha-melanocyte stimulating hormone during pregnancy in the rat. J Physiol. 2016;594(4):1087-1101. doi:10.1113/ JP271605

9. Hervey E, Hervey GR. The effects of progesterone on body weight and composition in the rat. $J$ Endocrinol. 1967;37(4):361-381. doi:10.1677/joe.0.0370361

10. Gerardo-Gettens T, Moore BJ, Stern JS, et al. Prolactin stimulates food intake in a dose-dependent manner. Am J Physiol. 1989;256(1 Pt 2):R276-R280. doi:10.1152/ajpregu.1989.256.1.R276

11. Caufriez A, Frankenne F, Hennen G, et al. Regulation of maternal IGF-I by placental GH in normal and abnormal human pregnancies. Am J Physiol. 1993;265(4 Pt 1):E572-E577. doi:10.1152/ajpendo.19 93.265.4.E572

12. Ma J, Pollak MN, Giovannucci E, et al. Prospective study of colorectal cancer risk in men and plasma levels of insulin-like growth factor (IGF)-I and IGF-binding protein-3. J Natl Cancer Inst. 1999;91(7):620-625. doi:10.1093/jnci/91.7.620
13. Cowley MA, Smart JL, Rubinstein M, et al. Leptin activates anorexigenic POMC neurons through a neural network in the arcuate nucleus. Nature. 2001;411(6836):480-484. doi:10.1038/35078085

14. Gustafson P, Ladyman SR, Brown RSE. Suppression of leptin transport into the brain contributes to leptin resistance during pregnancy in the mouse. Endocrinology. 2019;160(4):880-890. doi:10.1210/ en.2018-01065

15. Ladyman SR, Grattan DR. Suppression of leptin receptor messenger ribonucleic acid and leptin responsiveness in the ventromedial nucleus of the hypothalamus during pregnancy in the rat. Endocrinology. 2005;146(9):3868-3874. doi:10.1210/en.2005-0194

16. Page-Wilson G, Reitman-Ivashkov E, Meece K, et al. Cerebrospinal fluid levels of leptin, proopiomelanocortin, and agouti-related protein in human pregnancy: evidence for leptin resistance. J Clin Endocrinol Metab. 2013;98(1):264-271. doi:10.1210/jc.2012-2309

17. Andersson-Hall U, Svedin P, Andreasson U, et al. Central and peripheral leptin and agouti-related protein during and after pregnancy in relation to weight change. Clin Endocrinol. 2018;88(2):263-271. doi:10.1111/cen.13520

18. Geary M, Pringle PJ, Persaud M, et al. Leptin concentrations in maternal serum and cord blood: relationship to maternal anthropometry and fetal growth. Br J Obstet Gynaecol. 1999;106(10):10 54-1060. doi:10.1111/j.1471-0528.1999.tb08113.x

19. Maple-Brown L, Ye C, Hanley AJ, et al. Maternal pregravid weight is the primary determinant of serum leptin and its metabolic associations in pregnancy, irrespective of gestational glucose tolerance status. $J$ Clin Endocrinol Metab. 2012;97(11):4148-4155. doi:10.1210/jc.2012-2290

20. Butte NF, Hopkinson JM, Nicolson MA. Leptin in human reproduction: serum leptin levels in pregnant and lactating women. J Clin Endocrinol Metab. 1997;82(2):585-589. doi:10.1210/jcem.82.2.3731

21. Samano R, Martinez-Rojano H, Chico-Barba G, et al. Serum concentration of leptin in pregnant adolescents correlated with gestational weight gain, postpartum weight retention and newborn weight/length. Nutrients. 2017;9(10):1067. doi:10.3390/nu9101067

22. Franco-Sena AB, Rebelo F, Pinto T, et al. The effect of leptin concentrations and other maternal characteristics on gestational weight gain is different according to pre-gestational BMI: results from a prospective cohort. BJOG. 2016;123(11):1804-1813. doi:10.1111/1471-0528.13826

23. Lacroix M, Battista M-C, Doyon M, et al. Higher maternal leptin levels at second trimester are associated with subsequent greater gestational weight gain in late pregnancy. BMC Pregnancy Childbirth. 2016;16:62. doi:10.1186/s12884-016-0842-y

24. Stein TP, Scholl TO, Schluter MD, et al. Plasma leptin influences gestational weight gain and postpartum weight retention. Am J Clin Nutr. 1998;68(6):1236-1240. doi:10.1093/ajen/68.6.1236

25. Hauguel-de Mouzon S, Lepercq J, Catalano P. The known and unknown of leptin in pregnancy. Am J Obstet Gynecol. 2006;194 (6):1537-1545. doi:10.1016/j.ajog.2005.06.064

26. Sivan E, Whittaker PG, Sinha D, et al. Leptin in human pregnancy: the relationship with gestational hormones. Am J Obstet Gynecol. 1998;179(5):1128-1132. doi:10.1016/S0002-9378(98)70118-8

27. Masuzaki H, Ogawa Y, Sagawa N, et al. Nonadipose tissue production of leptin: leptin as a novel placenta-derived hormone in humans. Nat Med. 1997;3(9):1029-1033. doi:10.1038/nm0997-1029

28. Linnemann K, Malek A, Sager R, et al. Leptin production and release in the dually in vitro perfused human placenta. J Clin Endocrinol Metab. 2000;85(11):4298-4301. doi:10.1210/jcem.85.11.6933

29. Takahashi N, Waelput W, Guisez Y. Leptin is an endogenous protective protein against the toxicity exerted by tumor necrosis factor. J Exp Med. 1999;189(1):207-212. doi:10.1084/jem.189.1.207-a

30. Perez-Perez A, Toro A, Vilarino-Garcia T, et al. Leptin protects placental cells from apoptosis induced by acidic stress. Cell Tissue Res. 2019;375(3):733-742. doi:10.1007/s00441-018-2940-9

31. Schulz LC, Widmaier EP. The effect of leptin on mouse trophoblast cell invasion. Biol Reprod. 2004;71(6):1963-1967. doi:10.1095/ biolreprod.104.032722 
32. O'Leary P, Boyne P, Flett P, et al. Longitudinal assessment of changes in reproductive hormones during normal pregnancy. Clin Chem. 1991;37(5):667-672. doi:10.1093/clinchem/37.5.667

33. Boyne MS, Thame M, Bennett FI, et al. The relationship among circulating insulin-like growth factor (IGF)-I, IGF-binding proteins-1 and -2, and birth anthropometry: a prospective study. J Clin Endocrinol Metab. 2003;88(4):1687-1691. doi:10.1210/jc.2002-020633

34. Jones JI, Clemmons DR. Insulin-like growth factors and their binding proteins: biological actions. Endocr Rev. 1995;16(1):3-34. doi:10. 1210/edrv-16-1-3

35. Grueso E, Rocha M, Puerta M. Plasma and cerebrospinal fluid leptin levels are maintained despite enhanced food intake in progesterone-treated rats. Eur J Endocrinol. 2001;144(6):659-665. doi:10.1530/eje.0.1440659

36. Tritos NA, Segal-Lieberman G, Vezeridis PS, et al. Estradiol-induced anorexia is independent of leptin and melanin-concentrating hormone. Obes Res. 2004;12(4):716-724. doi:10.1038/oby.2004.84

37. Naef L, Woodside B. Prolactin/Leptin interactions in the control of food intake in rats. Endocrinology. 2007;148(12):5977-5983. doi:10. 1210/en.2007-0442

38. Ferraro ZM, Qiu Q, Gruslin A, et al. Excessive gestational weight gain and obesity contribute to altered expression of maternal insulin-like growth factor binding protein-3. Int $J$ Women Heal. 2013;5:657-665. doi:10.2147/IJWH.S49594
39. Andersson ES, Silventoinen K, Tynelius P, et al. Heritability of gestational weight gain-a Swedish register-based twin study. Twin Res Human Gene. 2015;18(4):410-418. doi:10.1017/thg.2015.38

40. Warrington NM, Richmond R, Fenstra B, et al. Maternal and fetal genetic contribution to gestational weight gain. Int J Obes. 2018;42 (4):775-784. doi:10.1038/ijo.2017.248

41. Gaillard R, Durmus B, Hofman A, et al. Risk factors and outcomes of maternal obesity and excessive weight gain during pregnancy. Obesity. 2013;21(5):1046-1055. doi:10.1002/oby.20088

42. Koren O, Good Rich J, Cullender T, et al. Host remodeling of the gut microbiome and metabolic changes during pregnancy. Cell. 2012;150:470-480. doi:10.1016/j.cell.2012.07.008

43. Lagiou P, Lagiou A, Samoli E, et al. Diet during pregnancy and levels of maternal pregnancy hormones in relation to the risk of breast cancer in the offspring. Eur J Cancer Prev. 2006;15(1):20-26. doi:10.1097/01.cej.0000186639.12249.c7

44. Lof M, Hilakivi-Clarke L, Sandin SS, et al. Dietary fat intake and gestational weight gain in relation to estradiol and progesterone plasma levels during pregnancy: a longitudinal study in Swedish women. BMC Women Heal. 2009;9:10. doi:10.1186/1472-6874-9-10

45. Headen I, Cohen AK, Mujahid M, et al. The accuracy of self-reported pregnancy-related weight: a systematic review. Obes Rev. 2017;18 (3):350-369. doi:10.1111/obr.12486

\section{Publish your work in this journal}

The International Journal of Women's Health is an international, peerreviewed open-access journal publishing original research, reports, editorials, reviews and commentaries on all aspects of women's healthcare including gynecology, obstetrics, and breast cancer. The manuscript management system is completely online and includes a very quick and fair peer-review system, which is all easy to use. Visit http://www.dovepress.com/testimonials.php to read real quotes from published authors. 